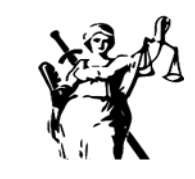

JUSTICIA

ISSN impreso 0124-744
ISSN digital $2590-456$

\title{
Neoliberalismo: análisis y discusión de su polisemia*
}

\section{Neoliberalism: analysis and discussion of its polysemy}

\author{
(iD) \\ Javier Orlando Aguirre-Román \\ Universidad Industrial de Santander, Colombia \\ jaguirre@uis.edu.co
}

\author{
Andrés Botero-Bernal \\ Universidad Industrial de Santander, Colombia \\ aboterob@uis.edu.co
}

\author{
Ana Patricia Pabón Mantilla \\ Universidad Autónoma de Bucaramanga, Colombia \\ apabon742@unab.edu.co
}

Recibido: 07 de noviembre de 2019 / Aceptado: 11 de febero de 2020

https://doi.org/10.17081/just.25.37.3523

\begin{abstract}
Resumen
El trabajo que se presenta tiene como objetivo distinguir, aclarar y dilucidar los diferentes usos de la noción de neoliberalismo. Se parte, en principio, de la multidimensionalidad del fenómeno del neoliberalismo, la cual se ve representada en diferentes formas de entenderlo y conceptualizarlo. Así, una vez analizada la polisemia del concepto y discutir los usos más relevantes del mismo, se pasa al análisis crítico de los resultados del análisis documental a partir de la pregunta acerca de si es posible desarrollar una visión coherente que dé cuenta de estas contradicciones y polisemias de forma crítica. Este resultado es producto de un registro sistemático, con base en la metodología analítica de investigación documental - bibliográfico. Como hallazgo de dicha indagación se exponen cinto sentidos del término neoliberal.
\end{abstract}

PALABras CLAVE: neoliberalismo ideológico, neoliberalismo político, neoliberalismo económico, neoliberalismo como gobernanza, homo oeconomicus.

\begin{abstract}
The text aims to distinguish, clarify and elucidate the different uses of the notion of neoliberalism. It accepts the multidimensionality of the phenomenon of neoliberalism, which is represented in the various ways of understanding and conceptualizing it. Once the polysemy of the concept has been analyzed, the text discusses to what extent it is possible to develop a coherent view of neoliberalism able to critically take into account these contradictions. The paper is based on the analytical methodology of documentary - bibliographic research. As a result of this investigation, five senses of the neoliberal term are presented.
\end{abstract}

KEYWORDS: ideological neoliberalism, political neoliberalism, economic neoliberalism, neoliberalism as governance, homo oeconomicus

\section{Como citar:}

Pabón Mantilla, A. P. (2020). Neoliberalismo: análisis y discusión de su polisemia. Justicia, 25(37), 109-124. https://doi.org/10.17081/ just.25.37.3523

El presente articulo es resultado del proyecto de investigación titulado "Las relaciones de tensión y complementariedad entre las principales manifestaciones cristianas latinoamericanas contemporáneas y el neoliberalismo global". Este proyecto es adelantado por el grupo de investigación Politeia de la Escuela de Filosofía de la Universidad Industrial de Santander. Es financiado mediante convocatoria interna de la Vicerrectoría Académica de la Universidad Industrial de Santander y se identifica con el Código 2516. 


\section{Introducción}

Es común escuchar el apelativo de neoliberal ante una persona, una institución o una política que realiza una acción o presenta una idea que se desaprueba. Sin embargo, al momento de precisar por qué alguien o algo es neoliberal, el asunto se dificulta. Esto se debe, entre otras cosas, a que esta palabra tiene diferentes acepciones y usos en la academia, en el mundo político y en la sociedad en general.

El presente trabajo da cuenta de un registro sistemático, con base en la metodología analítica de investigación documental - bibliográfico, que pretende distinguir, aclarar y dilucidar, los diferentes usos de la noción de neoliberalismo. Una vez realizado lo anterior se pasa a explorar esta noción desde una perspectiva crítica capaz de mostrar coherencia en un terreno ambiguo. Consideramos que si bien el pensamiento filosófico debe partir, en gran medida, de la intención de entender, conocer y clarificar, en este el caso, el significado de "neoliberal", es también necesario evitar que la confusión y la complejidad del tema nos lleven a un silencio cómplice.

Mencionaremos y discutiremos, desde la metodología señalada, cinco nociones generales del neoliberalismo, que no son absolutas y que pueden relacionarse entre sí, a la vez que contradecirse, lo que pone en evidencia que es una noción polisémica.

La estructura del texto es la siguiente: describiremos cinco niveles de posible comprensión del término "neoliberalismo" identificados en nuestra investigación, a saber, un neoliberalismo ideológico, uno político, uno económico, uno como gobernanza y, posteriormente, uno como el predominio de la subjetividad del homo oeconomicus. En la parte final del texto presentaremos una serie de conclusiones sobre la polisemia del concepto

\section{Neoliberalismo ideológico}

En general, si seguimos los usos más comunes del concepto, predomina lo que podríamos llamar un neoliberalismo ideológico, el cual tiene un sentido profundamente negativo. Esta visión negativa del neoliberalismo ofrecida por sus críticos, visión muy apropiada en varios casos, dio vía libre a que el término neoliberalismo se convirtiese en algo peyorativo en relación con el uso social del término.

Ahora bien, estas posturas críticas no siempre tienen en cuenta las diferentes características del neoliberalismo ni reconocen de entrada la ambigüedad del término, por lo cual, al final, todo cabe en el mismo "costal".

El término neoliberalismo ha pasado así a significar acusación, maldición y chivo expiatorio de un modelo de gobernanza política y económica* al que se le achacan todas las culpas, asociado a la alienación vía educación y vía medios de comunicación, a modelos dictatoriales (disfrazados de regímenes electorales), al patriarcado, a lo antiecológico y a lo hegemónico, incluso al que se le adjudica ser el resultado de ocultas conspiraciones de control mundial.

Sin embargo, esta palabra maldita puede servir para desviar la atención muchas veces sobre la gobernanza real. Es por ello que hemos denominado a este uso como ideológico, en remembranza del sentido que (Marx \& Engels, 1974) le dieron a esa palabra: la ideología, entendida como falsa conciencia del mundo,

* En la sección cuarta del texto explicaremos a qué nos referimos con la idea de un neoliberalismo como gobernanza. Por ahora baste señalar que hacemos alusión a las prácticas de gobierno efectivamente adoptadas. 
camufla los intereses de los realmente dominantes, por una parte, y permite que dichos intereses sean asumidos como propios por el conjunto de la sociedad, por la otra.

Lo cierto es que estos usos ideológicos de la palabra son muy imprecisos. Ya cualquier cosa odiada puede ser calificada como neoliberal a un punto que los que otrora se identificaban abiertamente con el término ya no gustan de ser considerados como tales, por los prejuicios que ello implica, y porque la gobernanza real a la que se suele llamar neoliberal no ha sido fiel necesariamente a las diferentes acepciones de neoliberalismo que mencionaremos en este texto. Para poner un ejemplo, recordemos que la forma de atender la crisis financiera global de 2008, en Estados Unidos, con el rescate de las instituciones financieras (en especial la banca de inversión), aspecto acusado como neoliberal, fue más un proyecto de intervencionismo económico del neoconservadurismo político, que varios neoliberales económicos y políticos (acepciones que veremos más adelante) criticaron duramente.

Además, en cierto sentido, muy propio de las paradojas lingüísticas con las que funciona el mundo del poder, ese afán ideologizante del término neoliberal que ahora analizamos coadyuva al modelo de gobernanza mismo. Esto por varios motivos:

$\gg$ i) termina siendo una forma de achacar en un "otro" (el neoliberalismo ambiguo) la responsabilidad de los males propios, lo que se suele llamar un "chivo expiatorio" que logra atraer las miradas inquisidoras dejando al entorno realmente problemático en relativa calma;

$\gg$ ii) logra desvirtuar la mirada de lo público sobre etiquetas y no sobre matices, lo que por demás ocupa el tiempo público de los ciudadanos al ponerlos a discutir sobre significantes y superficies en vez de significados y realidades complejas; y

$\gg$ iii) consolida un "malo absoluto" que, muchas veces, gobierna justo gracias a esa consideración, pues así sirve de mejor manera a los intereses particulares que lo sostienen y genera una desidia en los ciudadanos que los llevará, con el tiempo, a abandonar sus ideales públicos de reforma social.

De esta manera, la ideologización excesiva del término neoliberal tiene el riesgo de ayudar a erosionar lo público metiéndonos en una especie de círculo vicioso, pues esa erosión facilita que los culpables aumenten su poder y que los ciudadanos se desanimen en sus expectativas de rectificar el sistema. Esto es, que la demonización y la ambigüedad de una palabra de uso tan frecuente permite, junto a otros elementos, que se evite considerar que el problema puede estar más allá, como lo sería el propio Estado, según el anarquismo contemporáneo (Méndez \& Vallota, 2006) o en la perversidad endémica del ejercicio del poder en especial el de las macroorganizaciones, según la teoría crítica y la biopolítica, como la foucaultiana, por citar solamente dos posturas

Y nada mejor para este sistema ideológico que asegurar la pasividad y la apatía de la población, incluso por vía negativa, permitiendo primero diluir el significado para luego dar lugar a juicios rápidos de odio al significante, ayudado por el sistema de gobernanza, los medios de comunicación y el modelo educativo hegemónico. Y lo más agudo es cómo el sistema de gobernanza, que logró aprovecharse incluso de la visión peyorativa del significante neoliberalismo, logra imponer la idea de que cualquier rechazo real al modelo, es una amenaza a la democracia misma (Chomsky, 1988). 


\section{Neoliberalismo político}

Otro sentido que queremos resaltar de la palabra "neoliberalismo" se refiere al renacer del liberalismo político que emergió en las décadas inmediatamente siguientes a la Segunda Guerra Mundial. Renacimiento del liberalismo angloamericano, especialmente aquel que fue resultado de la aplicación constitucional en la carta de derechos inglesa y estadounidense a partir del individualismo e historicismo, modelos estos últimos que veían al naciente Estado moderno, en especial en lo que atañe al constitucionalismo estadounidense, como un peligro potencial para el ejercicio de las libertades básicas de los ciudadanos (Fioravanti, 1998) (Botero Bernal, 2016).

En este sentido, de forma general podemos señalar que como neoliberalismo se designó a la relectura y recontextualización de los autores liberales (fundamentalmente ingleses) e incluso ilustrados (incluyendo aquí desde los Enciclopedistas hasta Kant) de los siglos XVII y XVIII, con miras a soportar en dichas relecturas y recontextualizaciones el nuevo liberalismo que confrontaría discursivamente las perversiones estatalistas del siglo XX, incluso las totalitaristas, perversiones con diferentes orígenes y consecuencias según cada región y país.

La nota característica de este neoliberalismo político ha sido la reivindicación del individuo como centro del poder; aunque, para ser más precisos, debemos señalar que, más que del individuo, se trató de la reinvidación de sus libertades básicas, para cuya garantía se estatuyeron medidas de control sobre el aparato estatal (libertades negativas, en algunas tradiciones, o derechos de primera generación, en otras), base de lo que se designó como "Estado liberal".

De allí que este nuevo liberalismo político partió de la denuncia del estatalismo, al que acusó de fraguar el fracaso del Estado liberal, y propuso nuevos instrumentos que sí pudieran garantizar que el individuo y sus libertades no fueran nuevamente arrasados en pos de la seguridad nacional o el intervencionismo indebido del Estado.

Sin embargo, este neoliberalismo político tiene muchos ribetes a su interior, pues de un lado allí se encuadrarían autores del liberalismo moderado kantiano, como Rawls en sus primeros textos, hasta los neo-anárquicos que, hoy día, han consolidado su postura en dos líneas. Estas dos líneas tienen una especial relevancia puesto que, con el tiempo, una de ellas se ha llevado el mote de "neoliberalismo" mucho más que la otra.

Entre los neo-anárquicos encontramos, de un lado, la línea liderada por (Chomsky, 1973, 2007, 2014) y, del otro, la que encuadra a autores como (Hoppe, 2009, 2010, 2013), (Nozick, 1991) y Long, entre otros.

La primera línea podríamos llamarla como anarcosindicalismo o anarcosocialismo entendido esta como una especie de socialismo libertario que si bien no rechaza el liberalismo clásico tampoco puede ubicarse fácilmente en él, pues reivindica ideales socialistas en su seno (Chomsky, 2014) (Rocker, 1978). La segunda línea suele ser denominada como anarcocapitalismo o libertarismo, entendido esta como una especie de individualismo libertario.

Estas dos líneas, si bien están (muy) encontradas entre sí, en especial por la defensa o el rechazo al capitalismo, tienen enemigos comunes, en especial el estatalismo que reduce a su seno la política y la economía. Veamos. 
El control ejercido sobre la inversión, la producción, el comercio, las finanzas, las condiciones de trabajo y otros aspectos fundamentales de la política social está en manos privadas y lo mismo se aplica a la expresión, que está monopolizada por las grandes corporaciones que le venden el público a los anunciantes y que lógicamente refleja los intereses de los propietarios y su mercado. (Chomsky, 2007)

De manera tal que, para Chomsky, el Estado moderno, en especial con su democracia representativa, "se limita a la esfera política, sin tocar de forma alguna la esfera económica" (Chomsky, 2007).

Igualmente, Rothbard, desde la otra línea, dirá:

En última instancia, no existe un ente llamado «Administración Pública». Sólo existen personas que se reúnen en grupos, se dan el nombre de Gobierno o de Administración y actúan de forma "gubernamental». Toda propiedad es «privada». La única cuestión sujeta a debate es si está en manos de delincuentes o en las de sus verdaderos y legítimos dueños. Ésta es la única razón que lleva a los libertarios a oponerse a la formación de propiedades públicas o estatales y a abogar por su desaparición cuando se han formado: la comprobación de que los dirigentes del gobierno o del Estado son propietarios injustos de esta propiedad, de la que se han apoderado por procedimientos delictivos (Rothbard, 1995).

Por su parte, (Nozick, 1991), sigue la misma línea, al señalar que se justifica el Estado mínimo cuyas funciones sean "de protección contra la violencia, el robo y el fraude, de cumplimiento de contratos, etcétera, (...) el Estado no puede usar su aparato coactivo con el propósito de hacer que algunos ciudadanos ayuden a otros o para prohibirle a la gente actividades para su propio bien o protección" (p. 7). Igualmente, anarcocapitalista considera lo siguiente del Estado:

Un gobierno es un monopolista territorial de la coacción y la expropiación de los propietarios particulares, es decir, una agencia que de forma continua y permanente se permite violar los derechos de propiedad mediante la expropiación, los impuestos y las reglamentaciones. Presumiendo el interés personal de los agentes del gobierno, cabe esperar que todo Estado hará uso de su monopolio, manifestando una tendencia al aumento de la explotación. Sin embargo, no toda forma de gobierno tendrá idéntico éxito en su empresa o la ejecutará del mismo modo (Hoppe, 2013) (p. 89).

No podremos seguir indagando más al respecto, pues nos desviaría del interés que tenemos en este escrito. Basta con indicar que el anarcocapitalismo o libertalismo político, es quien se ha llevado en la acepción política, de mejor manera que otras corrientes, el apelativo de neoliberal. Esto en virtud de su cercanía con el neoliberalismo económico, aunque, repetimos, no son lo mismo, en especial por el énfasis en lo político que hace el anarcocapitalismo y la centralidad de lo económico en la acepción de la que hablaremos inmediatamente.

\section{Neoliberalismo económico}

En materia económica, en la década de los 60 y los 70, se empezó a designar así a un movimiento de las teorías monetaristas defendidas entre otros por la Escuela de Chicago, el ala económica de la Escuela Austriaca, y varias posturas institucionalistas, antidesarrollistas y antikeynesianas. Este movimiento ha sido liderado por (Stiglitz, 2002), (Friedman, 2002) y von Hayek, entre muchos otros. Fueron denominados así porque sus postulados han sido asemejados con una reconstrucción del liberalismo (ético, político y 
económico) especialmente el británico del siglo XVIII. Inicialmente, se trató de un movimiento rebelde en contra de los moldes político-económicos que surgieron del New Deal y que se mantuvieron incuestionados hasta los años 70 y 80, movimiento que contó con un altísimo prestigio por sus trabajos econométricos y de economía política que le merecieron varios premios nóbeles entre sus miembros. De forma general, podríamos decir que las prédicas esenciales de este movimiento han sido:

$\gg$ (i) el rechazo del estatalismo, tanto el promovido por "hombres malos del Kremlin" como por hombres bienintencionados (Friedman, 2002);

$\gg$ (ii) la defensa de un Estado mínimo dedicado a la protección de los derechos individuales, lo que supone para los autores moderados un Estado que regule, sin participar, la economía y los servicios públicos, y para los más radicales un Estado limitado a las tres funciones básicas federales estadounidenses (seguridad nacional, relaciones internacionales y administración tributaria) y por tanto sin poder siquiera ser un ente regulador (Codagnone, Bogliacino, \& Veltri, 2018);

$\gg$ (iii) el desmonte del Estado de Bienestar lo que supondría, entre otras cosas, entregar a particulares la prestación de los servicios públicos, al considerar que así mejoraban su eficiencia, y reducir al mínimo los subsidios en tanto que, creen ellos, los subsidios afectan la iniciativa privada y el libre mercado, todo lo cual redundaría en el interés general;

$\gg$ (vi) un control económico estatal fundado en el control de la inflación mediante políticas más que todo monetarias como el control del circulante;

$\gg$ (v) la defensa de un banco central autónomo que así equilibre cierta necesidad de regulación con la prohibición al Estado de intervenir la economía; y

$\gg$ (vi) el respeto máximo por la propiedad privada (individual) y la libertad (de empresa individual) como la manera de reinterpretarse, para finales del siglo pasado, el binomio de liberty \& property propio del Common Law y de las teorías individualismo angloamericanas de las que hablamos antes; entre las prédicas más conocidas.

Sin pretender ir más lejos, este movimiento pasó de la teoría a la acción gracias a la llegada al poder del conservadurismo político de Reagan, para Estados Unidos (esto es, el famoso Reaganomics), y de Thatcher, para Inglaterra, quienes dieron un impulso crucial para que el neoliberalismo económico dejase de ser una doctrina rebelde en las aulas y pasase a ser dominante en muchos discursos y escenarios políticos occidentales. Este hecho nos obliga a referirnos a un cuarto nivel en relación con el significado del término "neoliberal", esto es, al neoliberalismo como gobernanza.

\section{Neoliberalismo como gobernanza}

Como introducción a este cuarto sentido de la expresión "neoliberalismo" debemos hacer dos matices. El primero se refiere a que, con la aprobación política de las tesis del neoliberalismo en su acepción económica, se produjo un cambio en los actores y los protagonistas del movimiento, pues los ciudadanos, para la política (Breman, 2013) (Méndez \& Vallota, 2006), y los economicistas académicos, para la economía, fueron relevados en su capacidad propositiva e incluso decisoria por los policy makers y los tecnócratas de los gobiernos estatales y las instancias internacionales multilaterales (Stiglitz, 2002).

Esto es menester indicarlo porque el éxito del neoliberalismo como gobernanza implicó un distanciamiento relativo y paulatino del mismo frente al discurso de la Escuela de Chicago y de la austriaca, en tanto 
que muchos de los miembros de esta Escuela empezaron a criticar varias de las políticas económicas, supuestamente neoliberales pero al parecer más intervencionistas o neoconservadoras, de esos tecnócratas cada vez más poderosos en el gobierno Chomsky (Chomsky, 2004).

Justo de aquí proviene la confusión entre el neoliberalismo con el neoconservadurismo, a un punto que parecería ser más apropiado dejar de calificar ciertas políticas como "neoliberales" y mejor describirlas como "neoconservadoras" (Muñoz, 1999) (Chaves, 2013). Para mencionar un caso de los muchos posibles, el neoliberalismo económico se vio ante una encrucijada con la política de salvamento del sistema financiero (en especial de la banca de inversión) por parte de los Estados ante las crisis financieras de la primera década de este siglo, como la estadounidense del 2008, crisis que muchos consideran fue culpa de la desregularización del sistema financiero impuesto por el neoliberalismo tanto económico como el de gobernanza (Pollin, 2013).

Pero el mayor enfrentamiento acaece sobre cómo debió haberse respondido ante la crisis. Para algunos, debió haber sido necesario rescatar a los usuarios del sistema (no a los bancos) por medio, verbigracia, de una subvención al crédito (Pollin, 2013) y adoptar una política de seguridad nacional financiera que impidiera una interconexión sin regulaciones entre las entidades financieras de todo el mundo (O'Sullivan \& Kennedy, 2010). Para quienes piensan así, la acción del gobierno de imponer la austeridad [la cual "se diseñó para resolver la crisis de la 'deuda soberana', a fin de salvar el sistema bancario" (Stiglitz, 2012) y la de rescatar al sistema financiero fue una típica respuesta neoliberal.

En cambio, entre el nbrasieoliberalismo económico, los más fieles a su doctrina consideraron ese salvamento de los bancos como un intervencionismo injustificable del Estado, mientras que otros más moderados lo consideraron como un mal necesario (Eecke, 2013), pero ambas posturas neoliberales-económicas han aceptado, siendo generales, que este salvamento fue propio de un neoconservadurismo estatal pero más grave aún, uno que mediante subsidios distribuye la renta pública (fruto de la expropiación que el Estado hace de la propiedad privada vía impuestos) a los más favorecidos de la sociedad. En conclusión, la encrucijada está en que la acción estatal de salvar a los bancos fue vista por algunos como una medida neoliberal y, por otros, como una medida neoconservadora.

El segundo matiz atañe a la diferenciación entre neoliberalismo económico en el contexto estadounidense, de un lado, y en el inglés, del otro. Sin poder ir más lejos, en Estados Unidos, la Constitución federal (no necesariamente la de cada Estado de dicho país) estatuyó que el gobierno de la Unión está profundamente limitado, lo que sería una garantía a favor del individuo; es por ello que dicha Constitución contempló una compleja y fuerte red de checks and balances así como la limitación de la acción federal fundamentalmente a tres campos: la seguridad nacional (verbigracia, lo concerniente a las fuerzas armadas y los servicios de inteligencia, así como los hechos considerados vía legislativa como atentatorios contra la seguridad nacional, tales como el secuestro o el tráfico de drogas), los impuestos federales (recordemos, por ejemplo, cómo el ObamaCare pasó por el judicial review de la Corte Suprema con el argumento de que consistía básicamente un impuesto federal) y las relaciones exteriores.

En este sentido, defender la no intromisión del Estado federal en la vida de los individuos, en la propiedad e iniciativa privada, en la economía, etc., fue visto como una defensa de las libertades y del espíritu original de la Constitución de 1787 (Friedman, 2002). De allí que el partido Republicano y en especial el Tea Party se consideren como los legítimos defensores de los valores públicos con los que los Founding Fathers crearon dicho país; esto es, originalistas. Así, predicar un Estado mínimo desde las aulas de clase, especialmente en las facultades de economía, fue visto por cierto sector político conservador estadounidense como un desarrollo natural, en el campo económico fundamentalmente, de su Constitución. 
Dicho con otras palabras, decir por ejemplo que el gasto público debe reducirse a lo estrictamente necesario para mantener los derechos individuales, y que el rubro destinado a los gastos de defensa militar (recordemos el peso del gasto militar de Estados Unidos en su presupuesto general) debe ser el estrictamente necesario para garantizar la libertad de los estadounidenses ante amenazas externas (Friedman, 2002), es algo que suena muy diferente en Estados Unidos que en otros países que no han sido construidos a partir de una constitución marcadamente individualista.

Todo esto explica la fuerte relación entre el conservadurismo político del Partido Republicano con el neoliberalismo económico y la relativa facilidad con la que dicho modelo económico se implementó, y se defiende, por lo menos discursivamente, en dicho país. Claro está, como ya lo hemos señalado, esa defensa conservadora del neoliberalismo económico no fue tan desinteresada, ni tan fiel, al momento de poner en práctica las políticas estatales, una vez dichos conservadores asumieron el poder en Estados Unidos.

En cambio, Inglaterra, país que no renunció a su historicismo del Common Law, aunque sí lo revisitó para dar lugar al surgimiento del Estado moderno en el siglo XIX y XX, asumió como propio, incluso desde poco antes de la Segunda Guerra, el Welfare State, por lo que la llegada del neoliberalismo económico a dicho país fue mucho más problemática si se compara con lo acaecido en Estados Unidos, y de allí que los efectos y las críticas al neoliberalismo difieren sustancialmente a lado y lado del Atlántico.

Ahora bien, hechos estos dos matices, como lo señalamos líneas atrás, el neoliberalismo como gobernanza se refiere al paso de la teoría del neoliberalismo político y económico, a la acción política conservadora una vez en el poder, paso realizado, en principio, por los gobiernos de Ronald Reagan y de Margaret Thatcher, entre los más importantes. Inicialmente se concibió así al modelo de gobernanza que asumió como propio, no sin hacerle cambios importantes, el modelo económico en la díada atlántica de Reagan Tatcher, y que terminó siendo un caballito de batalla de organismos multilaterales como el FMI, el BM y el "Consenso de Washington", por dar tres ejemplos, aprovechando su capacidad de concretar pactos de poder con los espacios públicos de discusión y de reproducción de ideas (ahora concebido como un mercado más), esto es, de los medios de comunicación.

Un momento, claro está, en continua evolución, pues los retos del neoliberalismo como gobernanza han variado en los últimos 50 años, pasando del reto de la reforma del Estado y de los servicios públicos al de la defensa de un capitalismo global y la armonización de conceptos fundamentales de la política (como representación y participación) con las funciones del capital, fortalecidas por décadas de esta gobernanza multilateral de la que ya hablamos (Vargas, 2000).

En este sentido, un elemento fundamental del neoliberalismo como gobernanza es su carácter global con centros hegemónicos altamente intervencionistas. Elemento que también constituye, tal vez, el lado más crítico y negativo de este tipo de neoliberalismo. Por ejemplo, Vargas 2007 dice:

El Estado liberal nacional se ha convertido en un instrumento de colaboración del desarrollo del capitalismo transnacional. Los gobiernos de los Estados imperialistas transnacionales y las instituciones financieras internacionales de mayor influencia comparten un concepto del desarrollo global y del alivio de la pobreza centrado en la expansión económica sin límites de los mercados abiertos y de la liberalización del comercio. El Estado queda así en cautiverio, atrapado en la red de los intereses de los grupos nacionales dominantes que buscan la transnacionalización de la acumulación de sus capitales, mediante la penetración de las estructuras del poder del capitalismo (Jaramillo Pérez, Romero, Ramos, Angélica Pérez, \& María Suárez, 2010). 
Este neoliberalismo, como gobernanza, ya supera el paradigma del Estado Nación con el cual inició, erosionando a este último, pero con su permiso y auspicio (Chaves, 2013).

\begin{abstract}
Las tendencias recientes de globalización se orientan hacia la integración del mercado y la subordinación a las necesidades del capital; la homogeneización social y cultural; la desestructuración de la industria cultural endógena; el monopolio de los medios de comunicación; la libertad individual en menoscabo de la participación colectiva; la pérdida de garantías laborales y de seguridad social de los trabajadores y sindicatos; la pérdida de legitimidad del estado nación como ente soberano, sometido ahora al poder transnacional y a nuevas regulaciones para el desarrollo del comercio; la supresión de sus derechos sobre su propio espacio ((Wiesenfeld, 2006).
\end{abstract}

De allí que la posible contención del neoliberalismo, como gobernanza, ya escapa de las políticas y las normativas estatales, y pasa así a ser un problema de raigambre superior (Gandarilla Salgado, 2017) (Añez H \& Carmen, 2004), en la acción local y global (el famoso glocalismo). Por lo anterior, (Eugenia Bello de Arellano, 2000) asegura que la globalización, en relación con la noción de Estado, debe ser asumida desde otras perspectivas:

El llamado "orden o configuración mundial" ya no puede ser visto exclusivamente como un conjunto de naciones, sociedades nacionales o estados-naciones ni tampoco se puede decir que el individuo, ya como género humano, ya como totalidad social, sea asumido como el centro del mundo. Ambos entes, es decir, la nación y el individuo, siguen estando allí, plenos de realidad, pero ya no son los centros hegemónicos del pensamiento sino que han sido desplazados, subsumidos y hasta absorbidos por la sociedad global, por las configuraciones y movimientos de globalización, asunto que no puede ser ignorado (p. 56).

\title{
VI. El neoliberalismo como el predominio del homo oeconomicus
}

Esta quinta acepción de la noción de neoliberalismo la construiremos desde la perspectiva de la filósofa Wendy Brown. Consideramos que su visión es valiosa pues presenta una interpretación crítica del fenómeno del neoliberalismo en el marco de su compleja multidimensionalidad, tal y como la presentamos en las secciones anteriores. Se trata de una visión crítica pero no simplista ni reduccionista del neoliberalismo.

Para Brown el neoliberalismo es un fenómeno con una realidad sumamente compleja, a tal punto que, según sus propias palabras, el neoliberalismo

(...) intersects in Sweden with the continued legitimacy of welfarism, in South Africa with a post-Apartheid expectation of a democratizing and redistributive state, in China with Confucianism, post-Maoism, and capitalism, in the United States with a strange brew of long-established antistatism and new managerialism. Neoliberal policies also come through different portals and agents. While neoliberalism was an "experiment" imposed on Chile by Augusto Pinochet and the Chilean economists known as "the Chicago Boys" after their 1973 overthrow of Salvador Allende, it was the International Monetary Fund that imposed "structural adjustments" on the Global South over the next two decades. Similarly, while Margaret Thatcher and Ronald Reagan sought bold free-market reforms when they first came to power, neoliberalism also unfolded more subtly in Euro-Atlantic nations through techniques of governance usurping a democratic with an economic vocabulary and social consciousness (Wendy Brown, 2015)

Justicia Vol. 25 No. 37: pp. 109-124. Enero - Junio, 2020. https://doi.org/10.17081/just.25.37.3523 
Lo anterior muestra que si bien el neoliberalismo es un fenómeno "global y único", también se despliega de forma no unificada ni idéntica en los diferentes países y sociedades en los que se manifiesta, como ya lo hemos indicado en los apartados anteriores. De ahí que, como lo señala Brown, un primer paso para entender el fenómeno neoliberal exige partir de las siguientes contradicciones neoliberales en los niveles políticos y económicos.

Como un orden político, el neoliberalismo estructura mercados a la vez que pretende liberarlos de toda estructura; regula normativamente las subjetividades contemporáneas a la vez que pretende liberar al sujeto de todo orden normativo exterior; redefine los roles del Estado y lo fortalece en el desarrollo de estos a la vez que pretende mostrarse como un orden radicalmente alejado de los Estados y que pretende llevarlos a su mínima expresión.

De otra parte, como orden económico, el neoliberalismo pretende simultáneamente desregular y controlar los mercados; privatiza todo emprendimiento y toda iniciativa pública pero, a la vez, necesita de las asociaciones público - privadas que le infunden al mercado lenguajes éticos y de responsabilidad social y que le imprimen al ámbito público criterios de medición propios del mercado; y, finalmente, por su interés radical en la desregulación de los flujos de capital, debilita la soberanía nacional, mientras que, a la vez, crea preocupaciones nacionales relacionadas con el PIB, el PNB y otros indicadores de crecimiento económico similares (Wendy Brown, 2015).

Estas paradojas enrarecen y dificultan las discusiones académicas y políticas sobre el neoliberalismo, tal y como lo mostramos en los apartados anteriores, en especial en nuestras reflexiones sobre el neoliberalismo ideológico. Pero, ¿es posible desarrollar una visión coherente que de cuenta de estas contradicciones y polisemias sin que, a la vez, se quede en un silencio acrítico frente a ellas? ¿O debemos limitarnos en afirmar que el neoliberalismo no tiene un sistema fijo de coordenadas y que existen profundas variaciones geográficas y temporales en sus distintas aceptaciones ya vistas, sus implicaciones políticas y sus prácticas materiales? ¿O tal vez lo mejor sea simplemente dejar de usar el término neoliberalismo y decantarnos por críticas más concretas y puntuales?

Brown responde afirmativamente a la primera de esas preguntas y para no dejarse inmovilizar por las paradojas, las contradicciones y las polisemias del neoliberalismo, intenta escudriñar lo que existe más allá de las políticas económicas que el neoliberalismo parece encarnar, así como lo que subyace en las formas "neoliberales" de entender y desarrollar las relaciones entre el Estado y la economía.

Para dilucidar esto que está detrás, Brown se apoya en su lectura crítica de las lecciones de Foucault en el College de France 1978 - 1979. Desde Foucault, Brown postulará al neoliberalismo, en principio, como un orden normativo de razón que se encarna en una racionalidad política - gubernamental anclada en la subjetividad humana; todo lo cual le permite estructurar las diversas dimensiones de la vida humana a partir del posicionamiento de cierta subjetividad neoliberal (Wendy Brown, 2015).

Según Brown, lo que más llamaba la atención de Foucault sobre el neoliberalismo (que aquí hemos denominado como político y económico) era la reprogramación que éste hacía de los viejos principios liberales referidos a las relaciones y los fines del Estado, la economía y, en especial, los sujetos. De su lectura de Foucault, Brown concluye que lo propio del neoliberalismo, como orden normativo de razón, es su capacidad para producir cierta clase de sujetos. Por esto, de forma más concreta, Brown propondrá concebir al neoliberalismo como una fuerza productora de subjetividad, siendo esta la quinta acepción del término. Pero, ¿cuál subjetividad? ¿Qué tipo de sujeto produce el neoliberalismo?

Para entender y caracterizar esta subjetividad, es necesario notar dos elementos de esta fuerza que la 
produce: por una parte, su carácter histórico y, por la otra, su carácter trascendental.

Como fuerza histórica el neoliberalismo es una particular reacción académica, política y económica en contra del keynesianismo y del socialismo democrático. Como tal, tiene entonces diferentes orígenes de los cuales ya se ha hablado anteriormente. Y también se ha manifestado a través de diversos actores políticos que intentan modular el neoliberalismo de diferentes formas, como por ejemplo Gary Becker vs J. Stiglits, N. Sarkozy vs A. Merkel, G. Bush vs B. Obama. Igualmente, como fuerza histórica, deben notarse las diferencias entre los desarrollos del neoliberalismo como experimento en el Sur Global en contraste con el neoliberalismo como la nueva sociedad de mercado y las gobernanzas de R. Reagan y M. Thatcher, de las que ya hablamos.

Pero todo este desarrollo histórico, el cual quedó descrito en las secciones anteriores, se puede entender mejor si, a la vez, se asume una perspectiva trascendental sobre el neoliberalismo. Es decir, si nos atrevemos a pensarlo, además, como una fuerza que determina las condiciones de posibilidad de una realidad histórica nueva.

Como una fuerza trascendental, entonces, el neoliberalismo se entiende como una práctica que hace posible la economización de esferas y actividades anteriormente orientadas por otros valores y principios. Desde esta perspectiva, el neoliberalismo es una fuerza normativa que produce subjetividades. De ahí que, para Brown, más que un instrumento de gobernanza práctica, el neoliberalismo, como racionalidad política, es "the condition of possibility and legitimacy of its instruments, the field of normative reason from which governing is forged" (Wendy Brown, 2015). Por esto es global y unívoco pero también particular y no idéntico. Cuando se intersecta con culturas, tradiciones políticas, etc., toma diferentes formas, desarrolla diversos contenidos y adopta distintas normas.

Como racionalidad política, el neoliberalismo configura todos los aspectos de la existencia en términos económicos. De ahí que impacte las diversas asociaciones humanas, los pequeños negocios, las instituciones educativas (privadas o no), los museos, los procesos educativos, las lógicas deportivas, las instituciones prestadoras de servicios de salud, etc. La razón neoliberal en el sentido del que ahora hablamos, le da forma a las relaciones humanas en el trabajo, al derecho, a la educación, a la cultura y a la actividad cotidiana. Desde esta racionalidad, todas las conductas humanas se interpretan de forma económica; esto quiere decir que todas las dimensiones humanas se enmarcan y miden en términos y variables económicas. Lo que no implica necesariamente su monetarización. Somos y actuamos como sujetos económicos, así no haya dinero involucrado, en los ámbitos educativos, familiar, laboral, así como en relación con nuestra salud, nuestra vida amorosa, nuestro ocio, etc. (Posner, 1998)

Desde este punto de vista, podemos responder con facilidad a la pregunta por el tipo de sujeto producido por el neoliberalismo: se trata del homo oeconomicus (Demeulenaere, 2003). Pero, ¿quién es el homo oeconomicus? ¿Es un productor? ¿Un vendedor? ¿Un emprendedor? ¿Un consumidor? ¿Un inversionista? ¿Un cliente? Para Brown, el homo oeconomicus es, ante todo, un capital humano. Solo desde este nivel, el homo oeconomicus neoliberal llega a ser también un productor, un vendedor, un emprendedor, un consumidor, un inversionista, un cliente, etc (Foucault, 2004, p. 310). ¿Y qué significa ser un capital humano? La respuesta a este interrogante la encontramos en los siguientes tres niveles de análisis de esta subjetividad.

$\gg$ i) Como homo oeconomicus, el ser humano es homo oeconomicus y solamente homo oeconomicus en todo momento y lugar (Foucault, 2004). Como capital humano, lo somos para nosotros mismos en la medida en que concebimos nuestra subjetividad en términos económicos. Pero también lo hacemos con las demás relaciones que podemos tener: con nuestros amigos, con nuestros amores, con 
nuestros familiares, con el Estado, con nuestros empleadores, con nuestros colegas, etc. Incluso, según Brown, así nos concebimos y concebimos a los demás en el nuevo contexto de la constelación posnacional (Cortina, 2017).

De ahí que, como capital humano que somos en todo momento y lugar, nos concibamos a nosotros mismos como los principales responsables de nuestro bienestar, felicidad y posición individual en un mundo absolutamente competitivo con otros capitales humanos (Curran \& Hill, 2019). Pero, a la vez, en tanto capital humano para los demás, y en especial para las instituciones que nos "cobijan", somos lo que todo capital es, a saber, remplazables, prescindibles, usables. Sin garantías de seguridad, protección o sobrevivencia. En palabras de Brown, que vale la pena citar,

\begin{abstract}
A subject construed and constructed as human capital both for itself and for a firm or state is at persistent risk of failure, redundancy and abandonment through no doing of its own, regardless of how savvy and responsible it is. Fiscal crises, downsizing, outsourcing, furloughs - all these and more can jeopardize us, even when we have been savvy and responsible investors and entrepreneurs neoliberalism. Moreover, as a matter of political and moral meaning, human capitals do not have the standing of Kantian individuals, ends in themselves, intrinsically valuable. Nor do specifically political rights adhere to human capital; their status grows unclear and incoherent" (Wendy Brown, 2015)
\end{abstract}

El sujeto neoliberal es un sujeto que supuestamente está a cargo de sí mismo pero, simultáneamente, también es un sujeto que se debería saber instrumentalizable y potencialmente disponible y desechable en cualquier momento de "crisis".

$\gg$ ii) El homo oeconomicus como capital humano busca, ante todo, fortalecer su posición competitiva y apreciar cada vez más su valor. Más que un agente que intercambia sus intereses, sus productos y sus servicios en el mercado, el sujeto neoliberal es un agente que compite en el mercado con otros sujetos neoliberales. La esencia del mercado neoliberal no es el intercambio sino la competencia. Más que intercambiar nuestros productos con los otros, competimos con los otros por un mejor posicionamiento económico.

De esta manera, en un mundo de capitales humanos, la desigualdad y no la igualdad es el medio y la relación que nos une y define. Como capitales humanos la presunción natural de la igualdad como la relación primaria entre los seres humanos simplemente cesa de afirmarse. Como lo señala Brown, "equality ceases to be an a priori or fundament of neoliberalized democracy. In legislation, jurisprudence, and the popular imaginary, inequality becomes normal, even normative. A democracy composed of human capital features winners and losers, not equal treatment or equal protection" (Wendy Brown, 2015).

$\gg$ iii) El homo oeconomicus, como capital humano, es modelado como capital financiero o capital de inversión; se trata entonces de un capital humano financiarizado. "Its project is to selfinvest in ways that enhance its value or to attract investors through constant attention to its actual or figurative credit rating, and to do this across every sphere of its existence" (Wendy Brown, 2015). Así, El homo oeconomicus, construido como capital humano, es un sujeto gobernado por la finalidad de mejorar y apalancar permanentemente su posición competitiva. Es un sujeto que busca siempre aumentar su valor de portafolio, monetario o no, a través de todo tipo de esfuerzos, de allí el auge de la literatura de superación personal, entendiendo esto desde un sentido económico-competitivo, y el auge de la exigencia del emprendimiento como el nuevo motor de la formación de los nuevos ciudadanos.

El homo oeconomicus reduce al ser humano a un portafolio de valores y servicios en el que se invierte y se atrae inversionistas. Ya sea a través del número de seguidores en las redes sociales, los "me gusta" que 
se obtienen por las publicaciones, los rankings y las clasificaciones de todo tipo, o incluso a través de prácticas estructuradas de formas más monetarias, la educación, el tiempo libre, la reproducción, el consumo y, en general, todas las áreas de la experiencia humana se configuran a partir de decisiones y prácticas estratégicas que apuntan a realzar el valor propio en la competencia entre capitales (Wendy Brown, 2015).

Como capitales humanos financiarizados, el trabajo como categoría política se empieza a extinguir, así como las demás categorías socio - políticas derivadas de las relaciones de clase, como la alienación, la explotación, etc. La racionalidad que hace posible los sindicatos, los grupos de consumidores y otras formas de economía solidaria también se desmantela (Wendy Brown, 2015). De ahí que, como lo muestra Brown, las críticas al atomismo individualista que se dirigían al liberalismo clásico no sean válidas para el nuevo sujeto neoliberal. En efecto, el individuo potencialmente capaz de realizar luchas políticas es disuelto en un consenso político y ontológico radical en el que la totalidad de los seres humanos se integran como capitales humanos. Consenso e integración en el que que todos hemos aceptado nuestra subjetividad como homo oeconomicus que compiten de forma explícita e implícita entre sí. El individualismo, en el anterior sentido, no es entonces el rasgo definidor del homo oeconomicust.

\section{Conclusiones}

En el texto analizamos y expusimos la complejidad y la multidimensionalidad del concepto de neoliberalismo; características que, en los debates sociales y académicos, suelen no tenerse en cuenta. Por lo general, como lo señalamos en el primer acápite de nuestro texto al describir al neoliberalismo ideológico, el neoliberalismo se ha convertido en un significante profundamente negativo y peyorativo que poco a poco se ha venido quedando sin un significado preciso, lo que termina siendo muy útil para el funcionamiento de los sistemas perversos de las actuales macro-organizaciones, que se esconden detrás del "malo absoluto". Como consecuencia, quienes son catalogados como neoliberales no suelen identificarse así y prefieren los calificativos de pragmáticos, tecnócratas, eclécticos, etc (Arbeláez, 2018).

Por esta razón, y como un intento de alcanzar cierto grado de precisión en un contexto que reconocemos, por muchas razones, naturalmente ambiguo y confuso, presentamos cinco formas de entender el concepto de neoliberalismo. De ahí que habláramos de un neoliberalismo ideológico, un neoliberalismo político, un neoliberalismo económico, un neoliberalismo como gobernanza y, finalmente, un neoliberalismo como el predominio del homo oeconomicus.

Ahora bien, el método analítico con el que adelantamos la investigación explica estas divisiones de las categorías planteadas a lo largo del texto; divisiones que, naturalmente, no pueden ser entendidas como absolutas. Así lo intentamos mostrar cuando realizamos ciertas alusiones sobre las conexiones entre el neoliberalismo económico y el neoliberalismo como gobernanza por dar un caso. Igualmente, en la quinta y última acepción intentamos recoger elementos de todas las anteriores y mostrar, desde la visión de Wendy Brown, una perspectiva coherente y crítica pero no por esto reduccionista ni simplista del fenómeno del neoliberalismo. De ahí la mayor amplitud de nuestras reflexiones en tal acápite.

Esta posibilidad de recoger diversos elementos del fenómeno neoliberal y, a la vez, valorarlos críticamente, representa un gran valor en la propuesta de la filósofa estadounidense sobre el homo oeconomicus

$\dagger \quad$ En este sentido, la perspectiva de Brown se distingue con claridad tanto del neoliberalismo político como del económico en cuanto muestra que el neoliberalismo realmente no tiene un carácter individualista. 
como la subjetividad formada por la racionalidad normativo - política neoliberal dominante en nuestro presente.

Desde allí, podríamos atrevernos a postular, como manera general para aclarar y discutir este concepto de Brown, la existencia de cuatro modelos antropolíticos que describirían los últimos 3000 años de historia humana occidental.

En primer lugar, tendríamos al homo honoris, esto es, el ser humano que define su existencia en términos de lo que en la antigüedad se denominaba "honor" y desde el cual el sujeto se posicionaba en lo público. Nos referimos a ese sentimiento que motivaba a los antiguos griegos y romanos a todo tipo de sacrificios, como el reconocimiento a ser considerados héroes por la defensa del honor de la polis (o la civitas en Roma), del honor de la familia o del honor propio (Hannah, 1958). Un ejemplo de ello es los cargos políticos que raramente tenían remuneración, pues eran cargos Honoarios. Por el honor valía la pena morir o matar. Los sacrificios del individuo eran por el honor, a un punto que la riqueza estaba al servicio de conseguirlo, tal cual como era entendido en ese entonces.

Posteriormente aparecería el homo religiosus del Medioevo. Naturalmente este modelo se desarolla en medio de una tensión entre el homo honoris (nobles y militas) y el naciente homo religiosus (sacerdote y creyente) pero habría cierta inclinación por este último con el paso del tiempo, como lo relata (Dubby, 1999), poniendo como ejemplo las luchas entre nobleza y clero en torno al sistema matrimonial medieval. Así, la heroicidad y el reconocimiento social pasaban en buena medida por la fama de ser persona religiosa. Por la religión valía la pena morir o matar. Los sacrificios eran por Dios (ofrecidos a Dios), cosa que estudio Prodi en relación con el juramento (Prodi, 2009a), el fuero de la administración de justicia (Prodi, 2000) y el mercado (Prodi, 2009b).

En un tercer momento tendríamos al homo politicus-legalis de la Modernidad. Aunque difícilmente se puede afirmar que existía unidad de criterio sobre qué entender por política, lo cierto es que lo público, y por tanto lo jurídico, era el baremo del reconocimiento del otro como sujeto de derechos. Este es el periodo de la construcción de las nuevas entidades políticas, como el Estado Nación. Entidades por las cuales valía la pena morir o matar y a las cuales incluso se les consideraba como legitimadas para matar en la medida en que eran producto del designio divino, del orden natural o -según la teoría más dominante- del contrato social consolidado entre sujetos racionales de derecho que aceptaban explícita o tácitamente los derechos y los deberes derivados del mismo.

El mismo Foucault señala que el homo legalis, el sujeto de interés, es una criatura que aparece a partir de la afirmación de la soberanía del Estado moderno. Criatura que, no obstante, como lo señala Castro - Gómez, no era conciliable con el homo oeconomicus quien, a la larga, terminó imponiéndose (Castro Gómez, 2012).

Desde este punto de vista, en nuestra actualidad, eso que llamamos neoliberalismo, lo podemos entender como el predominio del homo oeconomicus, tal y como lo mostramos en la sección quinta de nuestro texto. Predominio que, por una parte, afecta todas esas dimensiones de la existencia humana que fueron dominantes en épocas anteriores pero que, por la otra, no implica que dejen de existir del todo. Lo que hace que en ellas sea posible encontrar formas de afirmar alternativas de vida que deben ser protegidas o renovadas. 


\section{Referencias}

Añez H, \& Carmen. (2004). El estado del bienestar social y el neoliberalismo ante los derechos laborales The State of Social Well-Being and Neoloberalism in the face of Labour Rights. Revista de Ciencias Sociales (RCS ), X(1), 70-82.

Arbeláez. (2018). "Duque se sale del libreto neoliberal ortodoxo y técnico" | La Silla Vacía. Retrieved July 29, 2020, from SILLA ACADÉMICA website: https://lasillavacia.com/silla-academica/universidad-de-los-andes-facultad-ciencias-sociales/duque-se-sale-del-libreto

Botero Bernal, A. (2016). Fioravanti visita Colombia: sobre la aplicación de los modelos de cartas de derechos constitucionales. Revista Filosofía UIS, 14(2), 15-46. https://doi.org/10.18273/revfil.v14n2-2015001

Breman, J. (2013). Crisis del capitalismo neoliberal, poder constituyente y democracia real. In Crisis del capitalismo neoliberal, poder constituyente y democracia real (pp. 61-108). Madrid: Traficantes de sueños.

Castro Gómez, S. (2012). Historia de la gubernamentabilidad. Razón de Estado, liberalismo y neoliberalismo en Michael Foucault. Ideas y Valores, 61(150), 245-256. Retrieved from https://revistas.unal.edu.co/ index.php/idval/article/view/27843

Chaves, P. (2013). Neoconservadurismo, neoliberalismo y protesta social: Un nuevo ciclo de protestas. In Crisis del capitalismo neoliberal, poder constituyente y democracia real (pp. 287-332). Madrid: Traficantes de sueños.

Chomsky, N. (1973). Por razones de Estado. Barcelona: Editorial Ariel.

Chomsky, N. (1988). Sobre el poder y la ideología: Conferencias de Managua. Madrid: Visor distribuciones.

Chomsky, N. (2004). Democracia y Mercados en el Nuevo Orden Mundial. Tafalla: Txalaparta.

Chomsky, N. (2007). Escritos libertarios: esperanza en el porvenir. Buenos Aires: Capital Intelectual.

Chomsky, N. (2014). Razones para la anarquía. Barcelona: Malpaso Ediciones S.L.

Codagnone, C., Bogliacino, F., \& Veltri, G. (2018). Scienza in vendita. Milano: Egea.

Cortina, A. (2017). Aporofobia, el rechazo al pobre. Un desafío para la democracia. Paidós.

Curran, T., \& Hill, A. P. (2019). Perfectionism is increasing over time: A meta-analysis of birth cohort differences from 1989 to 2016. Psychological Bulletin, 145(4), 410-429. https://doi.org/10.1037/bul0000138

Demeulenaere, P. (2003). Homo oeconomicus : Enquête sur la constitution d'un paradigme. Paris: Presses Universitaires de France - PUF.

Dubby, G. (1999). El caballero, la mujer y el cura. Madrid: Taurus.

Eecke, W. (2013). Ethical Reflections on the Financial Crisis 2007/2008. Washington: Georgetown University.

Eugenia Bello de Arellano, M. (2000). Algunas teorizaciones en torno a la globalización. In Aldea Mundo (Vol. 4). Retrieved from http://erevistas.saber.ula.ve/index.php/aldeamundo/article/view/8945

Fioravanti, M. (1998). Los derechos fundamentales: apuntes de historia de las constituciones. Madrid: Trotta.

Foucault, M. (2004). Nacimiento de la biopolítica. Curso en el College de France (1978 - 1979). Mexico: Fondo de Cultura Económica.

Friedman, M. (2002). Capitalism and Freedom. In Chigaco and London. Chicago.

Gandarilla Salgado, J. G. (2017). ¿De qué hablamos cuando hablamos de globalización?: una incursión metodológica desde América Latina. ÁNFORA, 14(22), 56-95. https://doi.org/10.30854/anf.v14.n22.2007.224

Hannah, A. (1958). La condición humana. Retrieved from www.planetadelibros.com

Hoppe, H. (2009). Libertad o socialismo. Quito: Universidad San Francisco de Quito. 
Hoppe, H. (2010). The Economics and Ethics of Private Property. In Studies in Political Economy and Philosophy. Retrieved from https://mises.org/library/economics-and-ethics-private-property-0

Hoppe, H. (2013). Democracia: el dios que fracasó (monarquía, democracia y orden natural). Madrid: Union Editorial.

Jaramillo Pérez, J. M., Romero, T. B., Ramos, L. M., Angélica Pérez, M., \& María Suárez, A. (2010). Significados de familia en el marco de la globalización. Revista de Investigaciones, 7(14), 59-79.

Marx, K., \& Engels, F. (1974). La ideología alemana. Ediciones Grijalbo.

Méndez, N., \& Vallota, A. (2006). Una perspectiva anarquista de la autogestión. Venezolana de Economía y Ciencias Sociales, 12(1), 59-72.

Muñoz, D. (1999). Reflexiones sobre el neoliberalismo. In Reflexiones sociológicas del neoliberalismo (pp. 209-234). Medellín: Universidad de San Buenaventura.

Nozick, R. (1991). Anarquía, Estado y utopía. Fondo de Cultura Económica.

O'Sullivan, K., \& Kennedy, T. (2010). What caused the Irish banking crisis? Journal of Financial Regulation and Compliance, 18(3), 224-242.

Pollin, R. (2013). La lucha para derrotar al neoliberalismo global. La centralidad de las políticas sobre los mercados fi nancieros en Ecuador y en otros lugares. In Crisis del capitalismo neoliberal, poder constituyente y democracia real.

Posner, R. (1998). El análisis económico del derecho. Mexico: Fondo de Cultura Económica.

Prodi, P. (2000). Una storia della giustizia: dal pluralismo dei fori al moderno dualismo tra coscienza e diritto. Bologna: Il Mulino.

Prodi, P. (2009a). Il sacramento del potere. Il giuramento politico nella storia costituzionale dell'Occidente. Bologna: Mulino.

Prodi, P. (2009b). Settimo non rubare. Furto e mercato nella storia dell'Occidente. Bologna: Il Mulino.

Rocker, R. (1978). Anarco sindicalismo (teoría práctica). Barcelona: Ediciones Picaso.

Rothbard, M. (1995). Ética de la libertad. Madrid: Union Editorial S.A.

Stiglitz, J. (2002). El malestar de la globalización. Mexico: Taurus.

Stiglitz, J. (2012). Necesita, 1\% de la población tiene lo que el 99\%. In El precio de la desigualdad. Bogota: Taurus.

Vargas, J. (2000). (2000). La Economía y la Reinvención del Estado Mexicano. Revista Electrónica de Epistemología de Ciencias Sociales, (8), 218-231.

Wendy Brown. (2015). Undoing the Demos: Neoliberalism's Stealth Revolution. Estados Unidos: MIT Press.

Wiesenfeld, E. (2006). El rescate de las comunidades en el marco de la Globalización. Athenea Digital. Revista de Pensamiento e Investigación Social, (9), 46-57. 